\title{
Preparedness Assessment for Disaster Management Among Dhahran Al Janoub General Hospital Staff During Hazm Storm Support $1436 / 2015$
}

\author{
Ahmed Ali Shammah ${ }^{1}$ \\ ${ }^{1}$ Department of Clinical Technology, Faculty of Applied Medical Science, EMS, Umm Al-Qura University, \\ Makkah, KSA \\ Correspondence: Ahmed Ali Shammah, Department of Clinical Technology, Faculty of Applied Medical Science, \\ EMS, Umm Al-Qura University, Makkah, KSA. Tel: 966-50-575-4217. E-mail: ahghamdi2@yahoo.com
}

Received: April 27, 2018 Accepted: May 20, 2018 Online Published: June 11, 2018

doi:10.5539/gjhs.v10n7p87 URL: https://doi.org/10.5539/gjhs.v10n7p87

\begin{abstract}
The hospital staff need to be competent to utilize the disaster plan to cope up with an emergency situation. Therefore, the present study has aimed to assess the knowledge of hospital staff of Dhahran Al Janoub General Hospital regarding the disaster management during Hazm Storm Support 1436/2015 in Saudi Arabia. The study has employed quantitative research design to assess the disaster management of hospital staff by recruiting 84 individuals (physicians, nurses, technicians, officers, and housekeepers) from Dhahran Al Janoub General Hospital. A questionnaire was given to respondents to gather information about disaster management. The obtained data was analysed using SPSS through chi-square analysis. The study results clearly depicted that the hospital staff with fewer years of experience had lesser knowledge about the disaster assessment as compared to the experienced employees. There was no statistically significant relationship identified between different job categories in the hospital and the level of knowledge about presence or absence of the emergency response plan. However, there was a statistically significant association found between different job professions and level of awareness regarding presence or absence of hospital command centres. The study concluded that the knowledge of emergency preparedness among the hospital staff was moderate and the hospital staff should participate and seek opportunities to prepare assessment for disaster management.
\end{abstract}

Keywords: disaster management, disaster, emergency preparedness, hospital staff

\section{Introduction}

Disaster is considered as an unpredicted, sudden, and overwhelming event, which results in significant physical change, destruction, drastic environmental change, and loss of life (Lurie et al., 2013) It causes disruptions in the functioning of a society or community through widespread human, economic, and environmental losses. It decreases the ability of affected society or community to cope up by utilizing the available resources. Among the developing countries, $95 \%$ of the deaths were caused by disasters (Sharma et al., 2016). Preparedness for disaster management is critical for businesses, household, and communities.

A mass disastrous event requires local coordination, individual responsibility, and effective planning to recover from major trauma. The concept of disaster preparedness aims to enhance the life safety during the disaster. It may include spills of hazardous materials, protective actions during the earthquake, and terrorist attacks. The preparedness for disasters includes different actions to enhance the ability for overcoming the emergency situation, protecting property, managing the disaster damage and disruption, and engaging in post-disaster restoration. Natural disasters generally affect the communities, people, and healthcare systems. Therefore, nurses and other healthcare professionals play an imperative role in the healthcare system, and ought to be prepared for the suitable response in the case of disaster.

The preparedness of nurses for disaster require proper planning, education, and training. They need to know appropriate disaster emergency plan to perform their role in disaster planning. A study conducted by Hammad et al. (2011) revealed that nurses were not confident regarding their role in disaster planning because they lacked adequate knowledge. Another study signified the importance of nurses' role in disaster management, apart from knowing the location of disaster plan (Whetzel et al., 2013). According to Al Khalaileh et al. (2011), knowledge of 
nurses about disaster plan was not adequate and they were poorly prepared for disaster and emergency planning. Moreover, the association between nurses' knowledge and their willingness to respond to a disaster event was weak (Veenema et al., 2008).

The industrial and technological advancements may increase the toll of man-made and natural disasters (Coppola, 2006). The disasters, causing losses and casualties, include high population density, oil and reservoir tank explosion, and presence of factories. In 2014, 202 disasters were reported; alone in Asia that injured 10,107 people (Seyedin et al., 2015). Disasters negatively affect health of a population, along with potential damage and disruption of infrastructure. It leads to long-term detrimental effects causing erosion of social development and loss of valuable assets. A study conducted by Alraga (2017) has shown that Saudi Arabia is developed as a multi-sectoral state that is capable of facilitating effective disaster management, despite of facing a great number of disasters.

It has been shown that there is a positive association between baseline knowledge of the nurses and perceptions of personal safety. Many man-made as well as natural disasters have been faced by Saudi Arabia, which include; earthquakes, floods, etc. The religious gatherings such as Umrah and Hajj impose man-made risks that have the potential to result in disaster and mass casualties. However, Saudi Arabia tends to employ the traditional health approach in disastrous situation within the country. Therefore, the present study has assessed the knowledge regarding disaster management during Hazm Storm Support 1436/2015 by recruiting employees of Dhahran Al Janoub General Hospital.

\section{Literature Review}

The health-care system plays a significant role in aiding and helping different communities from disasters. Prior training and nurses' experiences affect the preparedness and increase their self-confidence, skills, and awareness toward disaster response and lessen the susceptibility to impulsive events (O'Sullivan et al., 2008; Schultz et al., 2012). Few studies have shown that healthcare professionals are not ready to manage mass casualties; and their skills, education, and preparedness are not sufficient for a suitable response (Miller, 2011; Landry \& Stockton, 2008). Therefore, it is the foremost duty of the management to fulfil the training requirement of emergency department personnel as the front-line responders. Heavy damage and destruction are caused by the infrastructure of health-care and management system, resulting in the higher extent of injuries and mortality (Kenner \& Pressler, 2014). A timely and efficient response is required from the healthcare system to manage the consequences in affected areas. Therefore, there is a need to prepare for appropriate measures taken toward any disastrous condition. However, a study revealed that mostly nurses are not trained to manage mass casualties. Moreover, the preparedness, education, and skills of nurses are not satisfactory for an adequate response in a disastrous condition (Schultz et al., 2012).

Training of medical professionals is prioritized for providing care to the victims of the disaster. However, course development for training the medical personnel through standardized and well-accepted core competencies are severely lacking, which are required to develop disaster training courses (Schultz et al., 2012). Appropriate training of medical personnel ensures that they are prepared to treat patients and address different consequences during the catastrophic event. The emergency staff members at hospitals are the first service providers that render their services after an emergency or disaster. Therefore, it is necessary that the staff members have appropriate knowledge about the emergency preparedness (Miller, 2011). It is integral to the undergraduate nursing education that the nurses are well prepared for participating in planning and responding to a disastrous situation. The collaborative learning model needs to be used for teaching the undergraduate nursing students, regarding the preparedness of disaster management. The nurses employed in the military, public health, and emergency department are being entrusted to attend and manage the victims of disasters.

Preparedness assessment for disaster management is considered as a critical competency, which is required by the experienced nurses as well as fresh graduates. Collander et al. (2008) evaluated the disaster preparedness training course in order to teach principles of hospital disaster preparedness among the staff members. The results showed that Hospital Disaster Life Support (HDLS) course tends to provide multiple modalities for training the hospital staff and increase their knowledge level. The American Association of Colleges of Nursing has identified, that the nurses need to be prepared for attending and managing victims of bioterrorism and different mass casualty events. The nursing for disaster victims needs to preview towards emergency department nurses and military nurses. However, the preparedness has gained a requisite competency in the undergraduate nursing programs (Garbutt et al., 2008). Even, if the nurses are well trained in the community health education on natural disasters, they are still not efficient in managing bioterrorism and mass emergency events.

The nurses have basic knowledge and skills to manage a mass casualty incident. The assessment of training 
requirements is a significant step towards the implementation of specific training programs for the nurses. Good planning and preparedness among the hospital staff tend to reduce potential impact of disaster and implement effective approach during disastrous condition within the country (Top et al., 2008). A study was conducted by Lanzilotti et al. (2002) for determining the ability of physicians and nurses to identify and treat the victims, who are exposed to chemical and biological agents. The results revealed that the ability of physicians and nurses, to diagnose and treat the consequences of being exposed to chemical agents, was very low $(<8 \%)$. The majority of nurses were least willing to manage the victims, exposed to radiological incident (Lanzilotti et al., 2002).

\section{Methods}

The study has employed quantitative research design to study the assessment regarding disaster management during Hazm Storm Support 1436/2015. An observational study was conducted to inspect the preparedness assessment for disaster management. The data from the respondents was collected over a period of six months, from January 2016 to June 2016. The participants of the study were recruited through random sampling technique. A total of 100 questionnaires were distributed among the staff members of the Dhahran Al Janoub General Hospital including physicians, nurses, technicians, officers, and housekeepers. The questionnaires were distributed among the employees, seeking information regarding the emergency response plan, awareness about disaster, design, and policy of the hospital to control the disaster, security management plans, and other patient care information.

The participants were recruited to assess the preparedness of the hospital in case of disaster during the events of Hazm Storm Support 1436/ 2015. The questionnaire includes questions regarding different factors, which include command and control, communication, safety and security and infection control measures of the hospital. The questionnaire was based on 3 response options i.e. trichotomous (Yes, No and unknown). Out of 100, 84 questionnaires were received from the staff members with complete information. The sample size for the study was small because only Dhahran Al Janoub General Hospital was considered for the survey from Saudi Arabia.

The demographic profile of the participants has also been incorporated, including years of experience and qualification. However, the experience years were not recorded for the housekeepers and officers. The acquired data were analysed using the Statistical Package of Social Sciences SPSS (version 20.0). Chi-square test has been applied to examine the significance of the variables included in the study (command and control, communication, safety and security and infection control measures), as this statistical test is effective to observe the differences between variables (McHugh, 2013).

\section{Results}

The study has recruited 84 participants from Dhahran Al Janoub General Hospital, which include individuals from different professions. Table 1 shows the number of individuals recruited from different professions including physicians, nurses, officers, technicians, and housekeepers. The demographic profile of the respondents was also obtained, which is presented in Table 2 .

Table 1. Frequencies and percentages showing number of individuals recruited from each profession

\begin{tabular}{lll}
\hline Profession & Frequency & Percentage \\
\hline Doctor & 34 & $40.5 \%$ \\
Nurse & 31 & $36.9 \%$ \\
Technician & 11 & $13.1 \%$ \\
Officer & 4 & $4.8 \%$ \\
House keeper & 4 & $4.8 \%$ \\
Total & 84 & $100 \%$ \\
\hline
\end{tabular}


Table 2. Demographic profile of respondents

\begin{tabular}{lll}
\hline Physicians & Frequency & $\%$ \\
\hline Master degree & 30 & 88.2 \\
Doctor degree & 4 & 11.8 \\
Total & 34 & 100.0 \\
\hline Nurse & Frequency & $\%$ \\
\hline Technical institute & 28 & 90.3 \\
Bachelor & 3 & 9.7 \\
Postgraduate & 0 & 0 \\
Total & 31 & 100.0 \\
\hline Nurse & Frequency & $\%$ \\
\hline Diploma & 2 & 10.5 \\
Technical institute & 17 & 89.5 \\
Bachelor & 0 & 0 \\
Total & 19 & 100.0 \\
\hline Officer & Frequency & $\%$ \\
\hline Bachelor & 4 & 100 \\
Total & 4 & 100 \\
\hline House keeper & Frequency & $\%$ \\
\hline Educated & 3 & 75 \\
Illiterate & 1 & 25 \\
Total & 4 & 100 \\
\hline Experience & Frequency & $\% .6$ \\
\hline $1-5$ & 56 & 100 \\
$5-\quad 10$ & 15 & \\
$10-15$ & 5 & 73.7 \\
Total & & 0.7 \\
\hline & & \\
\hline
\end{tabular}

There was no statistically significant association between different job professions in the hospital and level of awareness about the emergency response plan. The results showed that there was a statistically significant association between different job professions and their level of awareness about presence or absence of hospital command centres (Table 2). More than $90 \%$ of the hospital staff including individuals from each profession were well-aware about the hospitals' emergency response plan. Moreover, majority of the hospital staff was well-aware about the presence of hospital command centre. The survey showed that inexperienced hospital staff was mainly not aware of emergency response plans; although, differences among the results were statistically insignificant. 
Table 3. Responses of hospital staff regarding the preparedness awareness of disaster management

\begin{tabular}{|c|c|c|c|c|c|c|}
\hline \multicolumn{7}{|c|}{ Awareness among hospital staff about emergency response plan } \\
\hline \multirow[t]{2}{*}{ Response } & \multicolumn{5}{|c|}{ Job Profession } & \\
\hline & Doctor & Nurse & Technician & Officer & House keeper & \\
\hline Yes & 30 & 27 & 10 & 3 & 2 & \multirow{4}{*}{$\begin{array}{l}\chi^{2}=12.8 \\
p=0.1\end{array}$} \\
\hline No & 1 & 2 & 0 & 1 & 0 & \\
\hline Unknown & 3 & 2 & 1 & 0 & 2 & \\
\hline Total & 34 & 31 & 11 & 4 & 4 & \\
\hline \multicolumn{7}{|c|}{ Awareness about presence of absence of hospital command centre among the hospital staff } \\
\hline \multirow[t]{2}{*}{ Response } & \multicolumn{5}{|c|}{ Job Profession } & \\
\hline & Doctor & Nurse & Technician & Officer & House keeper & \\
\hline Yes & 33 & 28 & 9 & 3 & 1 & \multirow{4}{*}{$\begin{array}{l}\chi^{2}=22.8 \\
\mathrm{p}=0.004\end{array}$} \\
\hline No & 0 & 1 & 1 & 1 & 1 & \\
\hline Unknown & 1 & 2 & 1 & 0 & 2 & \\
\hline Total & 34 & 31 & 11 & 4 & 4 & \\
\hline
\end{tabular}

The participants were also inquired about the presence of any poison centre during the chemical incident. The results revealed that there was a significant association between different job professions in the hospital and their level of awareness about the presence of poison centre during an emergency chemical incident (Table 3). Majority of the hospital staff agreed that there is an appropriate communication plan. Moreover, almost all of the hospital staff $(97.60 \%)$ agreed for the presence of the blue team in the hospital to initiate rapid response for the management of an emergency situation. The participants, who were not aware of these communication centres, were not experienced, professionals.

Table 4. Responses of hospital staff about presence of communication centres and code blue team in the hospital for in an emergency situation

\begin{tabular}{|c|c|c|c|c|c|c|}
\hline \multicolumn{7}{|c|}{ Awareness about communication centre to communicate with poison centre in chemical incident } \\
\hline \multirow[t]{2}{*}{ Response } & \multicolumn{5}{|c|}{ Job Profession } & \multirow[t]{2}{*}{ p-value } \\
\hline & Doctor & Nurse & Technician & Officer & House keeper & \\
\hline Yes & 30 & 28 & 9 & 3 & 2 & \multirow{4}{*}{$\begin{array}{l}\chi^{2}=12.3 \\
\mathrm{p}=0.137\end{array}$} \\
\hline No & 2 & 2 & 1 & 0 & 0 & \\
\hline Unknown & 2 & 1 & 1 & 1 & 2 & \\
\hline Total & 34 & 31 & 11 & 4 & 4 & \\
\hline \multicolumn{7}{|c|}{ Awareness about presence of code blue team in hospital for rapid response } \\
\hline \multirow[t]{2}{*}{ Response } & \multicolumn{5}{|c|}{ Job Profession } & \\
\hline & Doctor & Nurse & Technician & Officer & House keeper & \\
\hline Yes & 31 & 27 & 9 & 3 & 2 & \multirow{4}{*}{$\begin{array}{l}\chi^{2}=10.7 \\
\mathrm{p}=0.21\end{array}$} \\
\hline No & 1 & 2 & 1 & 0 & 0 & \\
\hline Unknown & 2 & 2 & 1 & 1 & 2 & \\
\hline Total & 34 & 31 & 11 & 4 & 4 & \\
\hline
\end{tabular}

The hospital staff was further questioned about hospitals' ability to receive the contents of protection (heavy gloves, glasses, heavy shoes, and chemical protective suits) during chemical incidents. The results revealed that there was a significant association between the hospital staff and their level of awareness about the hospital's ability to get 
access to protection during chemical incidents. Considering the presence of department for biological, radioactive, and chemical decontamination, the results showed that there was a positive association between the hospital staff and their level of knowledge about the importance of biological, radioactive, and chemical decontamination department in the hospital (Table 4).

The results also showed that association between different job professions in the hospital and their level of knowledge about the presence of designated trauma resuscitation room was statistically significant. It mainly includes a source of oxygen, focused abdominal sonography, pulse oximetry, chest tube, and portable x-ray. Moreover, there was a positive and significant association between the hospital staff and their level of knowledge about the importance of designated separated exposure and suturing wound department (Table 5).

Table 5. Responses of hospital staff regarding the access and presence of emergency departments in the hospital

\begin{tabular}{|c|c|c|c|c|c|c|}
\hline \multicolumn{7}{|c|}{ Access to contents of protection during chemical incidents } \\
\hline \multirow[t]{2}{*}{ Response } & \multicolumn{5}{|c|}{ Job Profession } & \\
\hline & Doctor & Nurse & Technician & Officer & House keeper & \\
\hline Yes & 32 & 27 & 9 & 3 & 1 & \multirow{4}{*}{$\begin{array}{l}\chi^{2}=16.4 \\
p=0.03\end{array}$} \\
\hline No & 1 & 2 & 1 & 0 & 1 & \\
\hline Unknown & 1 & 2 & 1 & 1 & 2 & \\
\hline Total & 34 & 31 & 11 & 4 & 4 & \\
\hline \multicolumn{7}{|c|}{ Awareness about presence of code blue team in hospital for rapid response } \\
\hline \multirow[t]{2}{*}{ Response } & \multicolumn{5}{|c|}{ Job Profession } & \\
\hline & Doctor & Nurse & Technician & Officer & House keeper & \\
\hline Yes & 32 & 28 & 8 & 4 & 2 & \multirow{4}{*}{$\begin{array}{l}\chi^{2}=19.3 \\
\mathrm{p}=0.013\end{array}$} \\
\hline No & 1 & 2 & 2 & 0 & 0 & \\
\hline Unknown & 1 & 1 & 1 & 0 & 2 & \\
\hline Total & 34 & 31 & 11 & 4 & 4 & \\
\hline \multicolumn{7}{|c|}{ Presence of designated trauma resuscitation room in the hospital } \\
\hline \multirow[t]{2}{*}{ Response } & \multicolumn{5}{|c|}{ Job Profession } & \\
\hline & Doctor & Nurse & Technician & Officer & House keeper & \\
\hline Yes & 32 & 28 & 9 & 4 & 1 & \multirow{4}{*}{$\begin{array}{l}\chi^{2}=19.07 \\
p=0.014\end{array}$} \\
\hline No & 1 & 1 & 0 & 0 & 1 & \\
\hline Unknown & 1 & 2 & 2 & 0 & 2 & \\
\hline Total & 34 & 31 & 11 & 4 & 4 & \\
\hline \multicolumn{7}{|c|}{ Presence of designated separate exposure and suturing wound department in the hospital } \\
\hline \multirow[t]{2}{*}{ Response } & \multicolumn{5}{|c|}{ Job Profession } & \\
\hline & Doctor & Nurse & Technician & Officer & House keeper & \\
\hline Yes & 32 & 27 & 9 & 3 & 1 & \multirow{4}{*}{$\begin{array}{l}\chi^{2}=20.3 \\
\mathrm{p}=0.009\end{array}$} \\
\hline No & 1 & 3 & 1 & 1 & 1 & \\
\hline Unknown & 1 & 1 & 1 & 0 & 2 & \\
\hline Total & 34 & 31 & 11 & 4 & 4 & \\
\hline
\end{tabular}

The hospital staff was questioned about the presence of infection control program in the hospital. The results depicted that there was a significant relationship between hospital staff and their knowledge about the presence of infection control program in the hospital. Moreover, there was a positive relationship between the hospital staff and their training regarding the control of different infections (Table 6). 
Table 6. Response of hospital staff regarding the presence of infection control program in the hospital and their training about the control of different infections

\begin{tabular}{|c|c|c|c|c|c|c|}
\hline \multicolumn{7}{|c|}{ Presence of infection control program in the hospital } \\
\hline \multirow[t]{2}{*}{ Response } & \multicolumn{5}{|c|}{ Job Profession } & \\
\hline & Doctor & Nurse & Technician & Officer & House keeper & \\
\hline Yes & 32 & 27 & 9 & 4 & 1 & \multirow{4}{*}{$\begin{array}{l}\chi^{2} \\
\mathrm{p}=0.02\end{array}$} \\
\hline No & 1 & 2 & 0 & 0 & 1 & \\
\hline Unknown & 1 & 2 & 2 & 0 & 2 & \\
\hline Total & 34 & 31 & 11 & 4 & 4 & \\
\hline \multicolumn{7}{|c|}{ Awareness about training of infection control among the hospital staff } \\
\hline \multirow[t]{2}{*}{ Response } & \multicolumn{5}{|c|}{ Job Profession } & \\
\hline & Doctor & Nurse & Technician & Officer & House keeper & \\
\hline Yes & 31 & 27 & 9 & 4 & 1 & $\chi^{2}$ \\
\hline No & 2 & 2 & 1 & 0 & 1 & $\mathrm{p}=0.04$ \\
\hline Unknown & 1 & 2 & 1 & 0 & 2 & \\
\hline Total & 34 & 31 & 11 & 4 & 4 & \\
\hline
\end{tabular}

\section{Discussion}

It is believed that framing a complete and comprehensive strategy for disaster response must evaluate training requirements of individuals (Landry \& Stockon, 2008; Garbutt, 2008). Low acquaintance about communication was observed among the nurses concerning the disaster preparedness (Inglesby, 2011). Although, nurses were aware of triage, but had the lowest acquaintance about communication. These results were also supported by Garbutt et al. (2008) and Sharma et al. (2016) that was found sensitive towards the disaster management but had a low level of awareness about it. Nurses were observed to be more informed as compared to other staff members; whereas, doctors were observed to have positive attitudes towards managing disaster situations.

A study conducted by Miller (2011) revealed that the hospital staff was more skilled in basic first aid and triage. However, they scored low, when they were asked about specific questions that included the application of antidotes to the biological agents. Therefore, the study stated that more educational programs should be conducted for management of emergency situations (Miller, 2011). There is a need for workshops, manoeuvres for staff, and annual training courses for the nurses to train them for emergency situations (Seyedin et al., 2015). Regarding the preparedness and perceived competence of nurses in managing the disaster, a study showed that the majority of nurses got confused when there was an emergency situation. The nurses were not confident in their abilities to give a rapid response to a major disaster event. However, the nurses, who were confident in their abilities, had an experience in shelters and disasters (Baack \& Alfred, 2013).

There is an increasing toll of natural and man-made disasters globally. Nurses are required to understand the cycle of national disaster management as they comprise of the highest percentage of medical and health workforce (Alzahrani \& Kyratsis, 2017). A study by Ibrahim (2014) targeted to assess the attitudes and familiarity concerning emergency and disaster preparedness among nurses in Saudi Arabia. The results suggested highly significant differences for the practice, attitude, and familiarity concerning natural disaster preparedness. The study reported lack of knowledge and emergency preparedness practices among nurses. Moreover, awareness and training regarding emergency situations must be conducted to enhance the nursing quality and practices to deal with an emergency. It has been observed that school faculties are unable to provide disaster preparedness curriculum in the nursing education (Djalali et al., 2013).

A study by Shalhoub et al. (2017) assessed the emergency or disaster preparedness for mass casualty situation in different private hospitals of Saudi Arabia. Many weaknesses were reported, particularly in the monitoring, training, and education of the hospital staff for the disaster emergency events. Few hospitals were found to conduct exercises with causalities, few had trained the staff in last twelve months; and none of the hospitals was observed to announce any exercise in the last year. Another study Bajow and Alkhalil (2014) shed light on the emergency disaster preparedness in the hospitals of Saudi Arabia, considering its increasing importance in the country. It was 
observed essentially for the hospitals in the country to understand many of the hospital disaster preparedness practices. Disaster and emergency plan; particularly in information, committee, preparedness and hazard map are required.

The study was motivated to find the disaster management preparedness among Dhahran Al Janoub General Hospital Staff during Hazm Storm Support 1436/2015. The results have provided novel insights related to suggestions. The hospital staff plays an important role in mitigation and recovery after the global increase in natural as well as human-induced disasters. The study concluded that the knowledge of emergency preparedness among the hospital staff was moderate. All the hospital staff should be involved in different aspects of disasters that include mitigation, planning, response, and recovery from any disastrous situation. The hospital should actively participate and seek opportunities to manage a disastrous event. Although, the attitude of the hospital staff was good and satisfactory, but their practices regarding the regularity of updating the emergency response need to be groomed. Moreover, administrators should encourage and support the disaster preparedness education of all the hospital staff for the promotion of hospital readiness in providing community care delivery in an emergency situation. The study was limited to Dhahran Al Janoub General Hospital Staff only; whereas, future studies may focus on other hospitals and recruit larger sample size to have more effective results.

\section{Acknowledgements}

The author is very thankful to all the associated personnel in any reference that contributed in/for the purpose of this research.

\section{Competing Interests Statement}

The author declares that there are no competing or potential conflicts of interest.

\section{References}

Al Khalaileh, M. A., Bond, E., \& Alasad, J. A. (2012). Jordanian nurses' perceptions of their preparedness for disaster management. International Emergency Nursing, 20(1), 14-23. https://doi.org/10.1016/j.ienj.2011.01.001

Alraga, S. M. (2017). An Investigation into Disaster Health Management in Saudi Arabia. Journal of Hospital \& Medical Management, 3(2).

Alzahrani, F., \& Kyratsis, Y. (2017). Emergency nurse disaster preparedness during mass gatherings: a cross-sectional survey of emergency nurses' perceptions in hospitals in Mecca, Saudi Arabia. BMJ open, 7(4), e013563. https://doi.org/10.1136/bmjopen-2016-013563

Baack, S., \& Alfred, D. (2013). Nurses' preparedness and perceived competence in managing disasters. Journal of Nursing Scholarship, 45(3), 281-287. https://doi.org/10.1111/jnu.12029

Bajow, N. A., \& Alkhalil, S. M. (2014). Evaluation and analysis of hospital disaster preparedness in Jeddah. Health, 6(19), 2668. https://doi.org/10.4236/health.2014.619306

Collander, B., Green, B., Millo, Y., Shamloo, C., Donnellan, J., \& DeAtley, C. (2008). Development of an "all-hazards" hospital disaster preparedness training course utilizing multi-modality teaching. Prehospital and disaster medicine, 23(1), 63-67. https://doi.org/10.1017/S1049023X00005598

Coppola, D. P. (2006). Introduction to international disaster management. Elsevier.

Djalali, A., Castren, M., Khankeh, H., Gryth, D., Radestad, M., Öhlen, G., \& Kurland, L. (2013). Hospital disaster preparedness as measured by functional capacity: a comparison between Iran and Sweden. Prehospital and disaster medicine, 28(5), 454-461. https://doi.org/10.1017/S1049023X13008807

Garbutt, S. J., Peltier, J. W., \& Fitzpatrick, J. J. (2008). Evaluation of an instrument to measure nurses' familiarity with emergency preparedness. Military medicine, 173(11), 1073-1077. https://doi.org/10.7205/MILMED.173.11.1073

Hammad, K. S., Arbon, P., \& Gebbie, K. M. (2011). Emergency nurses and disaster response: an exploration of South Australian emergency nurses' knowledge and perceptions of their roles in disaster response. Australasian Emergency Nursing Journal, 14(2), 87-94. https://doi.org/10.1016/j.aenj.2010.10.002

Ibrahim, F. A. A. (2014). Nurses' knowledge, attitudes, practices and familiarity regarding disaster and emergency preparedness-Saudi Arabia. American Journal of Nursing Science, 3(2), 18-25. https://doi.org/10.11648/j.ajns.20140302.12 
Inglesby, T. V. (2011). Progress in disaster planning and preparedness since 2001. Jama, 306(12), 1372-1373. https://doi.org/10.1001/jama.2011.1359

Kenner, C. A., \& Pressler, J. L. (2014). Developing a culture of emergency preparedness education in nursing. Nurse educator, 39(1), 1-3. https://doi.org/10.1097/NNE.0000000000000003

Landry, L. G., \& Stockton, A. (2008). Evaluation of a collaborative project in disaster preparedness. Nurse educator, 33(6), 254-258. https://doi.org/10.1097/01.NNE.0000334786.15052.d9

Lanzilotti, S. S., Galanin, D. J., Leoni, N., \& Craig, B. (2002). Hawaii medical professionals assessment.

Lurie, N., Manolio, T., Patterson, A. P., Collins, F., \& Frieden, T. (2013). Research as a part of public health emergency response. https://doi.org/10.1056/NEJMsb1209510

McHugh, M. L. (2013). The chi-square test of independence. Biochemia medica: Biochemia medica, 23(2), 143-149. https://doi.org/10.11613/BM.2013.018

Miller, P. (2011). An assessment of emergency department staff knowledge of emergency preparedness. Northern Kentucky University.

O'Sullivan, T. L., Dow, D., Turner, M. C., Lemyre, L., Corneil, W., Krewski, D., \& Amaratunga, C. A. (2008). Disaster and emergency management: Canadian nurses' perceptions of preparedness on hospital front lines. Prehospital and Disaster Medicine, 23(3), S11-S18.

Schultz, C. H., Koenig, K. L., Whiteside, M., \& Murray, R. (2012). Development of national standardized all-hazard disaster core competencies for acute care physicians, nurses, and EMS professionals. Annals of emergency medicine, 59(3), 196-208. https://doi.org/10.1016/j.annemergmed.2011.09.003

Seyedin, H., Dolatabadi, Z. A., \& Rajabifard, F. (2015). Emergency nurses' requirements for disaster preparedness. Trauma monthly, 20(4). https://doi.org/10.5812/traumamon.29033

Shalhoub, A. A. B., Khan, A. A., \& Alaska, Y. A. (2017). Evaluation of disaster preparedness for mass casualty incidents in private hospitals in Central Saudi Arabia. Saudi medical journal, 38(3), 302. https://doi.org/10.15537/smj.2017.3.17483

Sharma, S., Koushal, V., \& Pandey, N. (2016). Are our hospitals prepared for disasters? Evaluation of health-care staff vis-à-vis disaster management at a public hospital in India. International Journal of Health System and Disaster Management, 4(2), 63. https://doi.org/10.4103/2347-9019.183231

Top, M., Gider, Ö., \& Tas, Y. (2010). An investigation of hospital disaster preparedness in Turkey. Journal of Homeland Security and Emergency Management, 7(1). https://doi.org/10.2202/1547-7355.1781

Veenema, T. G., Walden, B., Feinstein, N., \& Williams, J. P. (2008). Factors affecting hospital-based nurses' willingness to respond to a radiation emergency. Disaster medicine and public health preparedness, 2(4), 224-229. https://doi.org/10.1097/DMP.0b013e31818a2b7a

Whetzel, E., Walker-Cillo, G., Chan, G. K., \& Trivett, J. (2013). Emergency nurse perceptions of individual and facility emergency preparedness. Journal of emergency nursing, 39(1), 46-52. https://doi.org/10.1016/j.jen.2011.08.005

\section{Copyrights}

Copyright for this article is retained by the author(s), with first publication rights granted to the journal.

This is an open-access article distributed under the terms and conditions of the Creative Commons Attribution license (http://creativecommons.org/licenses/by/4.0/). 